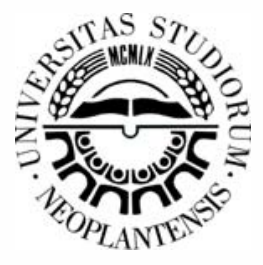

ADVANCED TECHNGLDGIES \& MATERIALS

http://journal-atm.org

\title{
The Optimization of Thermoforming Process Parameters in the Packaging of Medical Products
}

\author{
Edina Karabegović*, Redžo Đuzelić \\ University of Bihać, Faculty of Technical Engineering, Dr. Irfana Ljubijankića bb, 77000 Bihać, BiH
}

\begin{abstract}
The use of plastics has a very important role in the packaging of medical products. The choice of material and packaging process is important for the sustainability of the medical product quality, which has a direct impact on the user health. For the purpose of protection, depending on the type of medical product or the degree of risk to human health, the medical product packaging process is given a particular importance. Standard methods have been defined for performing the packaging process. In order to achieve the satisfactory quality of the packaging, and following the experimental analysis of the influence of thermoforming process parameters on the packaging design, the paper provides their optimum values. Minitab software was used for the analysis and optimization of the parameters.
\end{abstract}

Key words: medical packaging, thermoforming, parameters, optimization.

\section{INIRODUCTION}

Interest in the application of plastic products is increasing every day. It is well-known that plastic masses up to $35 \%$ are applied in industrial processes of packaging food, medical and other products, due to the basic characteristics of plastic materials that can be modified by any method for surface modification and/or material structure. A large number of published publications contain the results of testing parameters relevant to the structure and durability of plastic materials, including newer published publications based on a study on polymer nanocomposites [1]. Various types of plastic materials are used for the manufacture and packaging of medical products. The packaging process is performed depending on the type and classification of the medical product. Packing of medical products implies packaging production by thermoforming process, then placing products in packaging and sealing of finished packaging. The material used for packing medical products can be completely of polymeric origin or partly covered with porous medical paper. Research and analyses in the field are often focused on ecological protection of the environment. Goals and initiatives for contributing to the plastics industry by the European plastics industry also imply finding new solutions in packaging processes. New solutions are aimed at increasing re-use and plastic recycling up to $60 \%$ for the period up to 2030 [2]. In addition, research in this area has resulted in the introduction of appropriate important standards for the process of packing medical products and the quality control of the integrity of the packaged compound. Authors [3-5] have published the analyses of the methods for quality control of medical packaging. The paper by [6] lists the aspects of quality assurance in the production of medical products. Authors [7, 8] have published the analysis of the influence of process parameters in the packaging of medical products, modelling and optimization using the method of classical mathematical analysis and software analysis in Matlab and Minitab. Standard test methods for seal strength of flexible barrier materials were published by American Society for Testing and Materials (ASTM), under the designation F 88-07 [9]. The quality of the packaging depends directly on the properties of the material (foil) and the characteristics of the packaging process (thermoforming and sealing). This paper describes the process of thermoforming a medical foil package, which begins by heating the foil to a certain temperature, after which the air pressure forms the shape of the packing 
defined by the shape of the medical device. The influence of thermoforming process parameters was analysed separately for two phases (heating and forming). The Minitab software package was used for the analysis and optimization of the process parameters.

\section{THEPROCESS OF THERMOFORMING OF MEDICAL PACKAGING}

The packing of the medical product includes the process of film thermoforming into the packaging and closing the packaging after the medical product packing process. The packaging is performed on the machine of the Italian manufacturer AL.MA [10]. The starting material for the production of medical packaging is polypropylene / polyamide / polyethylene (PP /PA/PE), a co-extruded seven-layer film suitable for sterilization of ethylene oxide (EO). Typical film sizes, Steriking ${ }^{\circledR}$ ML P 80, have a specific weight of $78 \mathrm{~g} / \mathrm{m}^{2}$ and a thickness $d_{\mathrm{f}}=0.08 \mathrm{~mm}$. The packaging for a medical product is created by a thermal molding process according to a defined form in two phases: the film heating phase and the film forming phase. According to the recommendation of the film manufacturer, the temperature of the thermoforming process ranges from 80-120 . Test methods for ensuring the quality of thermoforming film products are described in Standard ASTM F88-07.

\section{MEASUREMENT AND OPTIMIZATON OF PROCESS PARAMEIERS}

Selection of Design of Experiments (DoE) options for the thermoforming process (two phases: heating and forming) was performed in the Minitab software package.

\subsection{Defining thermoforming process parameters}

Thermoformingprocess parameters for the first and the second phase are given in the Table 1.

Table 1-Thermoforming process parameters

\begin{tabular}{|c|c|c|c|c|}
\hline \multicolumn{5}{|c|}{ Thermoforming process parameters } \\
\hline $\begin{array}{c}\text { Process } \\
\text { phases } \\
(\mathrm{I}, \mathrm{II})\end{array}$ & \multicolumn{3}{|c|}{$\begin{array}{c}\text { Process input parameters } \\
T_{\mathrm{h}}, T_{\mathrm{f}},\left({ }^{\circ} \mathrm{C}\right) \\
T_{\mathrm{h}}, t_{\mathrm{f}}(\mathrm{s}) \\
p_{\mathrm{f}}(\mathrm{MPa}) \\
\end{array}$} & $\begin{array}{c}\text { Process } \\
\text { output } \\
\text { parameters } \\
d_{\mathrm{fm}}(\mu \mathrm{m})\end{array}$ \\
\hline \multirow{2}{*}{ (I) } & \multirow{2}{*}{$\begin{array}{l}\text { Heating } \\
\text { temperature }\end{array}$} & $T_{\mathrm{hmin}}$ & 85 & \multirow{10}{*}{$\begin{array}{l}\text { Average foil } \\
\text { thickness of } \\
\text { the formed } \\
\text { medical } \\
\text { packaging }\end{array}$} \\
\hline & & $T_{\text {hmax }}$ & 115 & \\
\hline \multirow{2}{*}{$\begin{array}{l}\text { Foil } \\
\text { heating }\end{array}$} & \multirow{2}{*}{$\begin{array}{l}\text { Heating } \\
\text { time }\end{array}$} & $T_{\mathrm{hmin}}$ & 1 & \\
\hline & & $T_{\text {hmax }}$ & 2 & \\
\hline \multirow{3}{*}{ (II) } & \multirow{2}{*}{$\begin{array}{l}\text { Forming } \\
\text { temperature }\end{array}$} & $T_{\text {fmin }}$ & 85 & \\
\hline & & $T_{\text {fmax }}$ & 115 & \\
\hline & \multirow{2}{*}{$\begin{array}{l}\text { Forming } \\
\text { time }\end{array}$} & $t_{\text {fimin }}$ & 1 & \\
\hline \multirow{3}{*}{$\begin{array}{l}\text { Foil } \\
\text { forming }\end{array}$} & & $t_{\text {fmax }}$ & 2 & \\
\hline & \multirow{2}{*}{$\begin{array}{l}\text { Forming } \\
\text { pressure }\end{array}$} & $p_{\text {fmin }}$ & $1.50 \cdot 10^{-1}$ & \\
\hline & & $p_{\text {fmax }}$ & $3.50 \cdot 10^{-1}$ & \\
\hline
\end{tabular}

Fig. 1(a) shows a part of the machine where thermoforming process and parameter measures as per process stages is conducted, according to the measuring positions, Fig. 1 (b). The temperature value $T$ of the first heating stage, represents the temperature of $10^{\circ} \mathrm{C}$, which is performed with the purpose of preheating the foil. In the analysis of the influence parameters, its value is viewed as $T=$ const, because it depends on the heating temperature $T_{\mathrm{h}}$ defined by the thermoforming process.

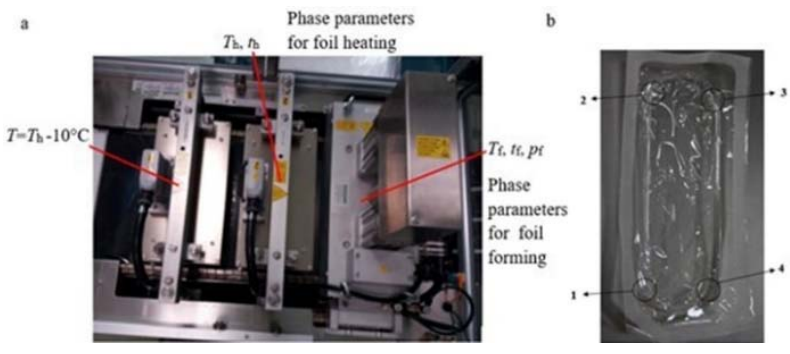

Fig. 1 Part of the machine for thermoforming process (a); sample with measuring positions. (b)

\subsubsection{Measuring results and analysis during the foil thermoforming process}

Planned measurements during the thermoforming process of the foil were performed separately for the foil heating phase (I) and the foil forming phase (II), as well as the analysis of the obtained results. The analysis of influential parameters and measurement results was performed in the Minitab software package, whose tools are based on statistical data processing. The test methodology is described by ASTM F2251-13 [9]. Measurement of the average foil thickness in the heating phase was performed for 16 experiments. During the test, the foil heating was conducted simultaneously for 4 samples (packaging). Four measuring points were defined on each of the samples, Fig. 1(b). The measurement results of the average foil thickness in the heating phase are given in Fig. 2.

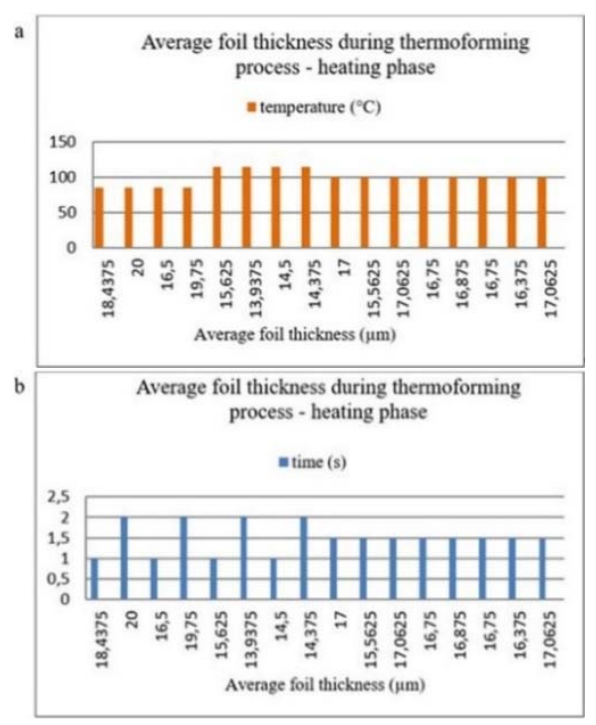

Fig. 2 The measurement results of the average foil thickness in the heating phase (a) average foil thickness in relation to temperature; (b) average foil thickness in relation to time. 
The significance of the influence of the process input parameters on the average foil thickness during the thermoforming process-heating phase is given in Fig. 3.

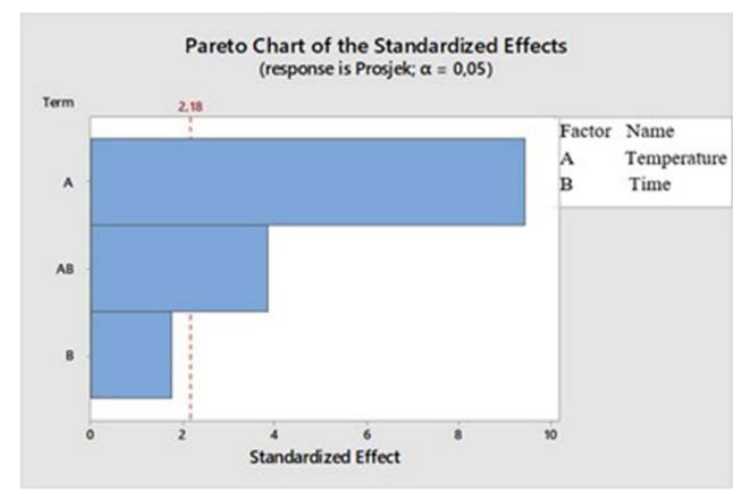

Fig. 3 Significance of the influence of process parameters during thermoforming-foil heating phase.

The Pareto diagram shows the significance of the influence of the input parameters on the average film thickness. The analysis of the obtained results, Fig. 3, indicates that the most influential input parameter during the foil heating phase is temperature (A). Another important parameter is the interactive effect of temperature and heating time (AB). Measurement of the average foil thickness in the forming phase was conducted on 12 experiments. Each of the experiments contains 4 samples (packaging), with 4 defined measuring points, Fig. 1(b). The number of input parameters at this stage of thermoforming is 3 (temperature, time and pressure). The results of measuring the average foil thickness in the packaging forming phase are given in Fig. 4.

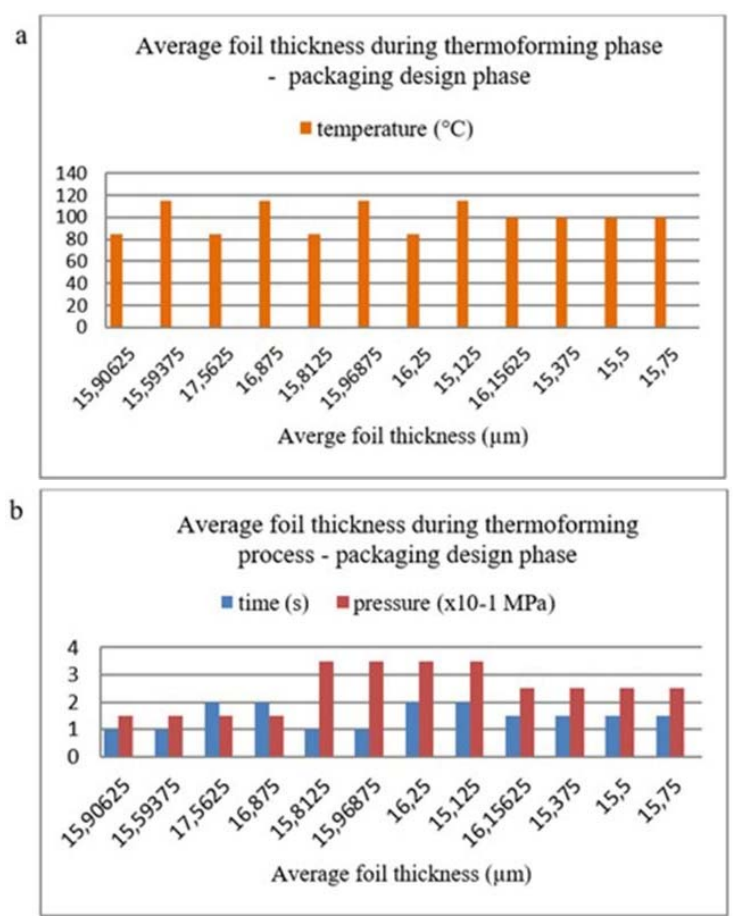

Fig. 4 Average foil thickness in the packaging forming phase in relation to a) temperature; (b) time and pressure.
The significance of the influence of the process input parameters on the average foil thickness in the forming phase is given in Fig. 5.

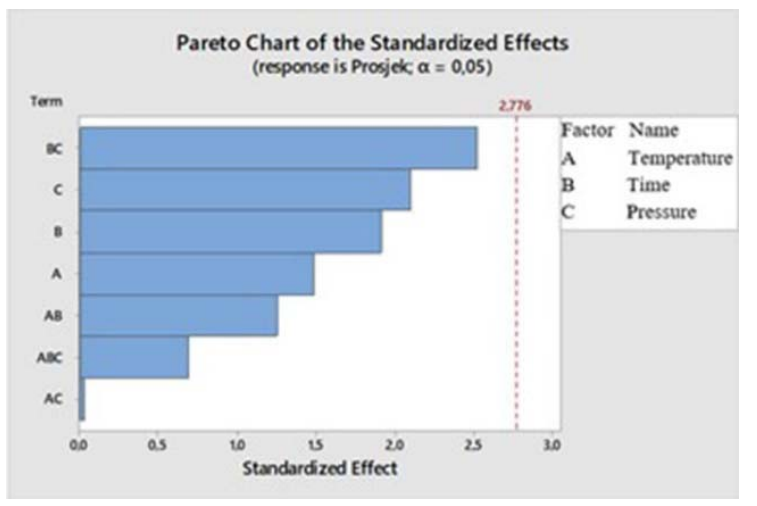

Fig. 5 Significance of the influence of process parameters during thermoforming-foil forming phase.

The significance of the influence of input parameters on the average foil thickness, Fig. 5, is less than expected, although the data of interactive air flow under pressure and the time should not be ignored.

\subsubsection{Optimization of the thermoforming process parameters}

The sizes corresponding to the maximum value of the average film thickness and the minimum deviation value were selected for the objective function. Fig. 6 shows diagrams of the influence of the input optimal sizes on the implementation of a given objective function.

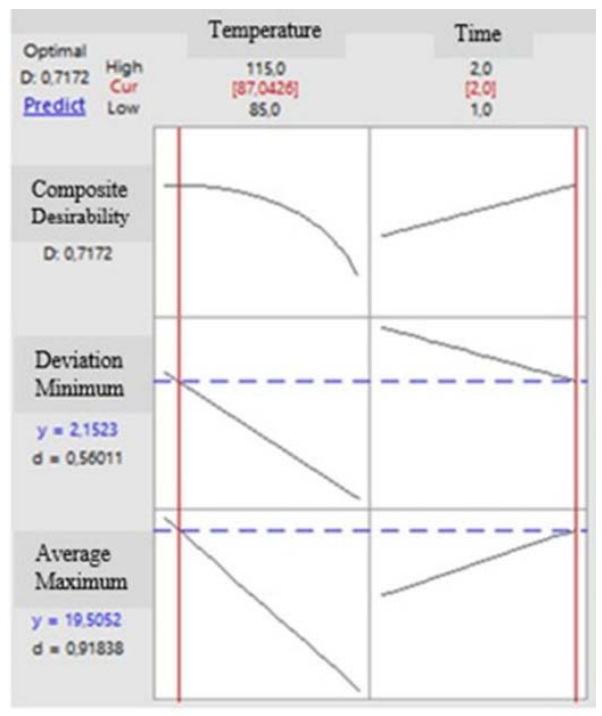

Fig. 6 Diagrams of the influence of the input optimal sizes.

The first part of the diagram (Composite Desirability) refers to the optimization of both output sizes (deviation and average film thickness) in relation to the input parameters of the heating phase (temperature and time). The second part of the diagram (Deviation Minimum) 
refers to the optimization of deviation depending on the input parameters (temperature and time), whereas the third part of the diagram (Average Maximum) refers to the maximum value of the average film thickness in relation to the input parameters (temperature and time).

According to the first diagram, the dependence of the output sizes on the process input parameters is about 71.20 $\%$, while the deviation for the same input parameter interval is 2.15 .

Optimization of the thermoforming process parameters was performed for the defined objective function $d_{\mathrm{fm}} \rightarrow \max$ $(\mu \mathrm{m})$, given in Table 2 .

Table 2-Optimum values of thermoforming process parameters

\begin{tabular}{|c|c|c|c|c|}
\hline \multicolumn{5}{|c|}{ Thermoforming process parameters } \\
\hline Process & $\begin{array}{r}\text { Opt } \\
\text { of in }\end{array}$ & $\begin{array}{l}\text { values } \\
\text { ameters } \\
\text { C) } \\
\text { ) }\end{array}$ & $\begin{array}{c}\text { Objecti } \\
\quad d_{\mathrm{fm}} \rightarrow \\
\text { (Average }\end{array}$ & tion \\
\hline \multirow{2}{*}{$\begin{array}{l}\text { Thermo- } \\
\text { forming } \\
\text { foil } \\
\text { heating } \\
\text { phase }\end{array}$} & $T_{\text {hop }}$ & 87 & \multirow[b]{2}{*}{$d_{\text {fmax }}$} & \multirow[b]{2}{*}{19.50} \\
\hline & $t_{\text {hop }}$ & 2 & & \\
\hline
\end{tabular}

\section{CONCLUSIONS}

The course and manner of conducting the medical product packaging process are defined by appropriate standards. There are several different ways of modelling and optimization to determine the optimum values of process parameters. By using Minitab software, we have obtained optimum values of process parameter in the size range defined by the appropriate standards. The optimum temperature for thermoforming-the foil heating phase is $T_{\text {hopt }}=87^{\circ} \mathrm{C}$, while the standard defined foil heating temperature is $T_{\mathrm{h}}=80^{\circ} \mathrm{C}-120^{\circ} \mathrm{C}$. The optimum heating time is $t_{\mathrm{opt}}=2 \mathrm{~s}$, whereas the standard defined time interval is 1 2 seconds.

The aim of this analysis and process parameter optimization is to maintain the reliable operation of the medical device packaging process by applying optimal process parameter values that, in addition to technological and economic justification, affect the quality of the medical device packaging. The technical and economic benefits of applying optimal parameter values are related to the following:

- Higher productivity,

- Savings in heating energy consumption,

- Material savings, and

- Greater stability of the thermoforming systems.

In addition to the above mentioned advantages, the production of packaging for medical products under optimal operating conditions has an impact on a higher level of environment protection.

\section{REFERENCES}

[1] Kádár, R., Wilhelm, M., Vittorias, I. and Mulone, A. (2018). Fourier-transform Dynamic mechanical thermal analysis - a new tool for the analysis of the thermo-rheological behavior of polymers and polymer sandwich composites. 16th International Conference on Deformation, Yield and Fracture of Polymers, At Kerkrade, Netherlands.

[2] PLASTICS EUROPEN, Association of Plastics Manufacturers, Brussels, 16-01-2018, from

https://www.plasticseurope.org/application/files/101 5/1966/6017/press_release.pdf, accessed on 2018-1010.

[3] Barcan, S. D. (1995). Using a Seal Matrix to Optimize Package Sealing Variables, Medical Device \& Diagnostic Industry 17, no. 9, 112-122.

[4] Franks, H. S. and Barcan, S. D. (1999). Comparing Tensile and Inflation Seal-Strength Tests for Medical Pouches, An MD\&DI.

[5] Franks, S. (2006). Seal Strength and Package Integrity -The Basics of Medical Package Testing, TM Electronics, Inc.

[6] Cristea, L., Baritz, M., Cotoros, D. and Repanovici, A. (2008). Aspects of quality assurance in medical devices production. 8th WSEAS International Conference on Signal Processing Computational Geometry and Artificial Vision (ISCGAV'08) Rhodes, Greece, 131-135.

[7] Hadžalić, M., Jurković, M., Hasanagić, R. (2018). Modeliranje i optimizacija sile otvaranja zavarenog spoja na mašini za pakovanje termoformiranjem, 9th International Scientific Conference on Production Engineering Development and Modernization of Production-RIM, Budva, Crna Gora, 57-62.

[8] Đuzelić, R. and Hadžalić, M. (2018). Effects and Optimization of Process Parameters on Seal Integrity for Terminally Sterilized Medical Devices Packaging, $10^{\text {th }}$ The International Symposium on Robotics and Biomedical Engineering-ISRBE, $10^{\text {th }}$ Days of BHAAAS in $\mathrm{BiH}$, Jahorina.

[9] ASTM F 88-07:2007 Standard Test Method for Seal Strength of Flexible Barrier Material ${ }^{1}$, ASTM International, USA.

ASTM F2251-13. Standard Test Method for Thickness Measurement of Flexible Packaging Material, ASTM International, USA.

[10] AL.MA. Srl Packing and Packaging Machinery: Thermoforming and in-line Blister Packing Machines, from http://www.almapackaging.com/en/automaticblister-packing-machines-for-medical-products.html, accessed on 2018-12-02. 